\title{
Evaluation of ethyl tert-butyl ether biodegradation in a contaminated aquifer by compound-specific isotope analysis and in situ microcosms
}

Petra Bombach ${ }^{1,2}$, Norbert Nägele ${ }^{3}$, Mònica Rosell ${ }^{1,4}$, Hans H. Richnow ${ }^{1}$, Anko Fischer ${ }^{2}$

${ }^{1}$ UFZ - Helmholtz Centre for Environmental Research, Department of Isotope Biogeochemistry, Permoserstrasse 15, D-04318 Leipzig, Germany

${ }^{2}$ Isodetect GmbH Leipzig, Deutscher Platz 5b, D-04103 Leipzig, Germany

${ }^{3}$ Kuvier the Biotech Company S.L., Ctra. N-I, p.k. 234 - P.E. INBISA 23a , E-09001 Burgos, Spain

${ }^{4}$ Current address: Grup de Mineralogia Aplicada i Medi Ambient, Departament de Cristal·lografia, Mineralogia i Dipòsits Minerals, Facultat de Geologia, Universitat de Barcelona (UB), C/Martí i Franquès s/n, 08028 Barcelona, Spain

\section{Corresponding author}

E-mail: petra.bombach@ufz.de

Phone: +493412351360

Fax: +49341235450822

Manuscript for Journal of Hazardous Materials 


\begin{abstract}
Ethyl tert-butyl ether (ETBE) is an upcoming groundwater pollutant in Europe whose environmental fate has been less investigated thus far. In the present study, we investigated the in situ biodegradation of ETBE in a fuel-contaminated aquifer using compound-specific stable isotope analysis (CSIA) and in situ microcosms in combination with total lipid fatty acid (TLFA)-stable isotope probing (SIP). In a first field investigation, CSIA revealed no significant carbon isotope fractionation but low hydrogen isotope fractionation of up to $+14 \%$ along the prevailing anoxic ETBE plume suggesting biodegradation of ETBE. Ten months later, oxygen injection was conducted to enhance the biodegradation of petroleum hydrocarbons $(\mathrm{PH})$ at the field site. Within the framework of this remediation measure, in situ microcosms loaded with $\left[{ }^{13} \mathrm{C}_{6}\right]$-ETBE (BACTRAP ${ }^{\circledR} \mathrm{s}$ ) were exposed for 119 days in selected groundwater wells to assess the biodegradation of ETBE by TLFA-SIP under the following conditions: (i) ETBE as main contaminant; (ii) ETBE as main contaminant subjected to oxygen injection; (iii) ETBE plus other PH; (iv) ETBE plus other PH subjected to oxygen injection. Under all conditions investigated, significant ${ }^{13} \mathrm{C}$-incorporation into microbial total lipid fatty acids extracted from the in situ microcosms was found, providing clear evidence of ETBE biodegradation.
\end{abstract}

\title{
Keywords
}

ETBE biodegradation; compound-specific stable isotope analysis (CSIA); in situ microcosm (BACTRAP); total lipid fatty acid-stable isotope probing (TLFA-SIP); groundwater remediation 


\section{Introduction}

Fuel oxygenates such as ethyl tert-butyl ether (ETBE), methyl tert-butyl ether (MTBE) and tert-amyl methyl ether (TAME) were introduced in the 1970s as octane enhancers to replace alkyl lead compounds in petrol which caused significant lead emission [1]. Since the promotion of the use of renewable energy in Europe as anchored in the European Directive 2003/30/EC and later repealed by the Directive 2009/28/EC [2, 3], ETBE becomes increasingly important in Europe. In contrast to MTBE, ETBE can be produced from isobutene and bioethanol which is accounted as a biofuel and is partly promoted by tax incentives. As a result, the production of ETBE increases rapidly in Europe with a production capacity of over 3,500 ktons per year in 2010 [1]. Despite the high practice standards when handling fuel oxygenates, their intensive use has considerable risks for the environment. Recent studies have demonstrated that ETBE is already occasionally being found in surface water and groundwater among Europe $[4,5]$. Also in the U.S. where fuel oxygenates have been intensively used since the 1970s, several groundwater contaminations by ETBE were detected [6]. When ETBE is accidentally released into the subsurface, it rapidly disperses in the environment due to its high water solubility and low reactivity with organic matter. The low odor and flavor thresholds in water of 1-2 $\mu \mathrm{g}$ ETBE $\mathrm{L}^{-1}[4]$ makes drinking water resources easily unpalatable.

Due to the expected increase in ETBE contaminated sites, viable remediation strategies are required to tackle this environmental problem. Monitored Natural Attenuation (MNA) and Enhanced Natural Attenuation (ENA) concepts are increasingly implemented for the management of contaminated sites [7]. The decision-making process to employ MNA or ENA for site cleanup requires a comprehensive understanding of the site-specific biodegradation processes [8]. In general, ETBE is recalcitrant to biodegradation due to its tertiary carbon atom and ether bond. Hitherto, there are only few strains isolated that are able to use ETBE aerobically as a sole carbon and energy source [9-12]. Furthermore, co-metabolic degradation of ETBE by propane-oxidizing and tetrahydrofuran-oxidizing bacteria has been observed [13, 
14]. The potential for ETBE biodegradation under anoxic conditions was demonstrated in microcosms with previously uncontaminated soil [15], but several other laboratory microcosm studies testing for anaerobic ETBE degradation have yielded negative results unlike for MTBE or TAME [16-18].

Suitable monitoring methods to explore in situ ETBE biodegradation are scarce. In a recent study, the evaluation of ETBE biodegradation in an aquifer impacted by a leaking gas station was pioneered using compound-specific stable isotope analysis (CSIA), laboratory microcosms and a catabolic gene approach [5]. While indigenous groundwater microorganisms able to degrade ETBE aerobically could successfully be enriched, no evidence for ETBE biodegradation could be provided along the contaminant plume using carbon and hydrogen stable isotope analysis. Additionally, in an on-site pilot plant filled with contaminated groundwater and inoculated with an ETBE-degrading consortium with the purpose of bioaugmentation, an increase in the $e t h B$ gene copy number, the gene which encodes the cytochrome P450 monooygenase involved in the ETBE biodegradation, was recorded and suggested the growth of ETBE degraders [19].

Despite the first step was done to explore the intrinsic Natural Attenuation potential at a field site, novel methods and strategies are needed to assess in situ ETBE biodegradation. The objective of this study was to evaluate the in situ ETBE biodegradation in a fuel-contaminated aquifer considering different hydrochemical conditions. First, CSIA was applied. CSIA is based on the change of stable isotope ratios due to biodegradation processes resulting in the enrichment of the heavy isotope $\left(\right.$ e.g. ${ }^{13} \mathrm{C},{ }^{2} \mathrm{H}$ ) in the residual contaminant fraction (for review see [20-22]). Isotope fractionation during the biodegradation of ETBE has been evaluated for several ETBE-degrading strains [14, 23, 24]. In the second step, in situ microcosms loaded with ${ }^{13} \mathrm{C}$-labeled ETBE (BACTRAP ${ }^{\circledR} \mathrm{S}$ ) were applied in the framework of a field trial to enhance the biodegradation of petroleum hydrocarbons $(\mathrm{PH})$ by oxygen injection into groundwater. Whether the addition of oxygen to anoxic aquifers will result in a stimulation of ETBE 
degradation has been not clarified thus far. Additionally, the potential effects of the coexistence of other water-soluble petroleum compounds such as benzene, toluene, ethylbenzene and xylenes (BTEX) as well as MTBE on ETBE biodegradation has not been addressed for field sites. Laboratory studies with pure strains have shown that ETBE degradation rates can increase in the presence of other 15 petroleum compounds compared to when tested alone which was attributed to a co-metabolic ETBE degradation. However, the same study proved a negative effect caused by the presence of BTEX, whereas MTBE did not have any impact [11]. Data on the effect of the simultaneous presence of MTBE, ETBE and PH (including BTEX) are of great importance because in case of fuel accidents, $\mathrm{PH}$ and at least one fuel oxygenate will co-occur in a contaminated aquifer whereas in countries that shifted from MTBE to ETBE, both oxygenates can occur. In situ microcosms in combination with ${ }^{13} \mathrm{C}$-labeled compounds aim to reveal carbon assimilation patterns within intrinsic microbial communities. The approach has been employed successfully to prove the microbial transformation and assimilation of common groundwater pollutants like MTBE [25], benzene and toluene [26-28], monochlorobenzene [29, 30] as well as naphthalene and fluorene [31] in contaminated aquifers. In this study, we developed a specific in situ microcosm system to trace the microbial fate of ETBE. Our field investigation focused on (i) the assessment of ETBE biodegradation in the field considering different hydrochemical conditions and (ii) to compare the effectiveness of both methods (CSIA and BACTRAP ${ }^{\circledR}$ ) for assessing ETBE biodegradation.

\section{Materials and methods}

\subsection{Field site}

The site is located in the Central West of Spain. In 2007, a tank truck accident caused significant soil and groundwater contaminations with ETBE and MTBE as well as aliphatic and aromatic hydrocarbons. The geological and hydrogeological conditions are highly heterogeneous 
throughout the entire field site as five different geological formations were affected by the contamination. The aquifer zone mainly affected by the contamination consists of schist and quartzite. Due to measures for danger prevention and remediation including drainage under parts of the spill and a pump \& treat system as well as strong seasonal variations of the groundwater level, groundwater flow directions were highly heterogeneous and could not be clearly defined.

\subsection{Hydrochemical analysis}

The concentration of dissolved oxygen, $\mathrm{pH}$ and temperature was measured in situ using a multiparameter probe HANNA HI 9828 (HANNA $^{\circledR}$ instruments). Prior to groundwater sampling, at least 3 volumes of the sampling well were purged. From each monitoring well, one $500 \mathrm{~mL}$ glass bottle was completely filled with groundwater and sealed with Teflon lined screw caps for total petroleum hydrocarbon (TPH) analysis. Samples were preserved immediately with sulfuric acid $\left(0.1 \%(\mathrm{v} / \mathrm{v}) \mathrm{H}_{2} \mathrm{SO}_{4}\right)$. For concentration analysis of BTEX, MTBE and ETBE, two $120 \mathrm{~mL}$ serum bottles were completely filled with groundwater, crimp closed with Teflon coated butyl rubber stoppers and preserved with sulfuric acid $\left(0.1 \%(\mathrm{v} / \mathrm{v}) \mathrm{H}_{2} \mathrm{SO}_{4}\right)$. Anions and cations were measured in non-preserved samples. All samples were stored at $4^{\circ} \mathrm{C}$ in the darkness until analysis. Concentrations of the major contaminants, anions and cations as well as of methane were determined according to the following standard methods: BTEX, MTBE and ETBE (DIN 38407-F9-1), TPH (DIN EN ISO 9377-2), methane (EDI-guideline chapter 2, GC-FID), sulfate and nitrate (DIN EN ISO 10304-1, ion chromatography - IC), sulfide (DIN EN ISO 10304-3, IC), iron and manganese (DIN EN ISO 11885, inductively coupled plasma optical emission spectrometry - ICP-OES).

\subsection{Compound-specific stable isotope analysis (CSIA) of ETBE}

Samples for CSIA were taken in December 2010. In total, 9 monitoring wells were selected so that all zones of contamination including source, plume and fringes were represented. From 
each monitoring well, $1 \mathrm{~L}$ glass bottle was completely filled with groundwater and sealed with Teflon lined screw caps. Samples were preserved immediately with trisodium phosphate dodecahydrate $\left(1 \%(\mathrm{w} / \mathrm{w}) \mathrm{Na}_{3} \mathrm{PO}_{4} \cdot 12 \mathrm{H}_{2} \mathrm{O}\right)$ and stored at $4{ }^{\circ} \mathrm{C}$ in the darkness until isotope analysis.

Purge and trap (P\&T) coupled to gas chromatography isotope ratio mass spectrometry (GCIRMS) was applied to determine carbon and hydrogen stable isotope ratios of ETBE in the groundwater samples as described elsewhere [5]. All samples were measured in at least two replicates. Isotope ratios are expressed in the delta notation $\left(\delta^{13} \mathrm{C}, \delta^{2} \mathrm{H}\right)$ relative to an international standard according to [32]:

$$
\delta^{13} C \text { or } \delta^{2} H=\frac{R_{\text {sample }}}{R_{\text {standard }}}-1
$$

where $\mathrm{R}_{\text {sample }}$ and $\mathrm{R}_{\text {standard }}$ are the ${ }^{13} \mathrm{C} /{ }^{12} \mathrm{C}$-ratios and ${ }^{2} \mathrm{H} /{ }^{1} \mathrm{H}$-ratios of the sample and an international standard, respectively. Vienna Pee Dee Belemnite (VPDB, ${ }^{13} \mathrm{C} /{ }^{12} \mathrm{C}=(11237.2 \pm$ 2.9) $\left.\times 10^{-6}\right)$ ) was used as international standard for carbon isotope analysis and Vienna Standard Mean Ocean Water $\left(\right.$ VSMOW, $\left.\left.{ }^{2} \mathrm{H} /{ }^{1} \mathrm{H}=(155.76 \pm 0.05) \times 10^{-6}\right)\right)$ as international standard for the hydrogen isotope analysis [33]. The $\delta^{13} \mathrm{C}$ - and $\delta^{2} \mathrm{H}$-values are reported in per mil (\%o). The reproducibility of isotope analysis for ETBE exhibited standard deviations $(2 \sigma) \leq \pm 0.3 \%$ for carbon and $\leq \pm 7 \%$ for hydrogen, respectively.

\subsection{In situ microcosms}

The in situ microcosm study was conducted in September 2011. The in situ microcosm system (BACTRAP $^{\circledR}$ ) was prepared as previously described [26] with modifications of the carrier material. A perforated Teflon tube of $5 \mathrm{~cm}$ length and $1 \mathrm{~cm}$ diameter with a perforation of 1 $\mathrm{mm}$ was filled with $0.5 \mathrm{~g}$ activated carbon pellets (Biocoal, Silcarbon Aktivkohle GmbH, Kirchhundem, Germany) and $0.15 \mathrm{~g}$ of the resin Dowex ${ }^{\circledR}$ Optipore L493 (Sigma-Aldrich). The 
activated carbon pellets served as surface for microbial colonization [34] and were before BACTRAP preparation heated for 4 hours at $300^{\circ} \mathrm{C}$ to remove organic residues. Optipore L493 has been proven for its high sorption affinity and slow desorption for MTBE [35] and was therefore used as adsorbent agent for ${ }^{13} \mathrm{C}$-labeled ETBE and additional surface for microbial colonization. For precondition, Optipore L493 was washed with ethanol and distilled water as described elsewhere [36]. After removing of ethanol residues using a vacuum-pump, the resin was dried for 2.5 days at $90^{\circ} \mathrm{C}$ and placed in small hand-made acetone-rinsed ethylenetetrafluoroethylene bags (mesh size: $70 \mu \mathrm{m}$; Stockhausen, Germany; one bag per BACTRAP). In total, 4 BACTRAPs were prepared. Following the preparation, all BACTRAPs were autoclaved at $121^{\circ} \mathrm{C}$ for sterilization and hydration and were loaded each with $50 \mathrm{mg}$ of $\left[{ }^{13} \mathrm{C}_{6}\right]-$ ETBE (Sigma-Aldrich) via gas phase under reduced pressure as described elsewhere [26]. All microcosms were transported and stored in anoxic sterile water until their installation in monitoring wells. At the field site, each BACTRAP was fixed to a polypropylene rope and deployed in the monitoring wells PZ1, PZ8, PZ12 and PZ17 at $1.5-3.7 \mathrm{~m}$ below groundwater level. In wells PZ1 and PZ17, oxygen injection systems with membrane diffusor of $1 \mathrm{~m}$ length providing oxygen with a rate of $2 \mathrm{~g} \mathrm{~h}^{-1}$ were installed $1 \mathrm{~m}$ above the BACTRAPs. Wells PZ8 and PZ12 served as controls to evaluate the $\left[{ }^{13} \mathrm{C}_{6}\right]$-ETBE biodegradation under unaltered redox conditions. After 119 days of incubation, the BACTRAPs were recovered and immediately transferred to sterile Falcon tubes on dry ice. BACTRAPs were stored at $-80^{\circ} \mathrm{C}$ until further analysis.

\subsection{Fatty acid and isotope analysis}

Total lipids were extracted from the mixture of activated carbon pellets and Optipore L493 using a modified protocol of Bligh and Dyer as described elsewhere [26]. Lipids were transesterified to fatty acid methyl esters (FAMEs) by a mild alkaline methanolysis [37] and dissolved in $n$-hexane containing $20.06 \mu \mathrm{g} \mathrm{mL}^{-1}$ of 21:0 FAME as internal standard (Sigma- 
Aldrich, Germany). In order to check if the pretreated Optipore L493 and activated carbon pellets (without field incubation) contained any fatty acids, they were extracted in the same manner.

For identification and quantification of FAMEs, gas chromatography-mass spectrometry (GCMS) was used as described elsewhere [38]. The fatty acids were designated according to the nomenclature described elsewhere [39]. Carbon isotope ratios of FAMEs were analyzed using a GC-IRMS instrument as described recently [38]. The carbon isotope ratios of fatty acids were reported in $\delta$-notation according to Eq. 1 . The $\delta^{13} \mathrm{C}$-values of the fatty acids were corrected for the carbon introduced during derivatization [40].

\section{Results}

\subsection{Hydrochemical characteristics of the fuel-contaminated aquifer during CSIA}

At the time of the CSIA monitoring campaign (December 2010), concentration of total petroleum hydrocarbons (TPH) was up to $31 \mathrm{mg} \mathrm{L}^{-1}$ in the aquifer (see Supporting Information (SI), Table S1). In addition, high concentrations of volatile organic compounds (VOCs) such as ETBE (up to 5,300 $\mu \mathrm{g} \mathrm{L}^{-1}$ ), BTEX (up to 2,220 $\mu \mathrm{g} \mathrm{L}^{-1}$ ) and MTBE (up to $420 \mu \mathrm{g} \mathrm{L}^{-1}$ ) were found. The groundwater contamination has formed distinct plumes of TPH and VOCs, with an ETBE plume of about $170 \mathrm{~m}$ length and $110 \mathrm{~m}$ width (Figure 1). Hydrochemical conditions in the investigated aquifer were complex and mainly influenced by the distribution of the contaminants, water table fluctuation and pump \& treat treatment. Elevated methane concentrations (up to $300 \mu \mathrm{g} \mathrm{L}^{-1}$ ) and sulfide formation (up to $1.3 \mathrm{mg} \mathrm{L}^{-1}$ ) were found in groundwater wells with high concentrations of VOC. Nitrate was depleted to concentration below the detection limit of $2.2 \mathrm{mg} \mathrm{L}^{-1}$ in high contaminated groundwater wells while concentration up to $14.1 \mathrm{mg} \mathrm{L}^{-1}$ and nitrite production were found in the fringe of the TPH and 
VOC plumes. Iron and manganese showed relative low concentrations (up to $4.4 \mathrm{mg} \mathrm{L}^{-1}$ ) in all investigated groundwater wells (see SI, Table S1).

\subsection{CSIA of ETBE}

Groundwater from wells PZ1, PZ14 and PZ15 exhibited the highest ETBE concentrations with values up to 5,200 $\mu \mathrm{g} \mathrm{L}^{-1}$ and can thus be regarded as representing the contaminant source (see Figure 1 and Table $\mathrm{S} 1$ in the SI). In these wells, the $\delta^{13} \mathrm{C}$ - and $\delta^{2} \mathrm{H}$-values ranged from -25.4 to -25.8 and -126 to $-148 \%$, respectively (Figure 1$)$. Similar $\delta^{13} \mathrm{C}$-values (-25.3 to $-25.9 \%$ ) were found in all wells along the ETBE plume independent of changes in ETBE concentration. Taking into consideration the analytical uncertainty of $\pm 7 \%$ for hydrogen stable isotope analysis, slight changes in the $\delta^{2} \mathrm{H}$-values of ETBE of maximal $+14 \%$ as compared to the most positive isotope value found in the zone of the contaminant source (PZ1: $-126 \%$ ) were observed in two groundwater wells (PZ3, PZ9) with ETBE concentrations smaller than $100 \mu \mathrm{g}$

$\mathrm{L}^{-1}$. By contrast, no significant differences in the $\delta^{2} \mathrm{H}$-values could be found for other wells with ETBE concentration in the same order of magnitude (PZ12, PZ13, PZ17) (see Figure 1 and Table $\mathrm{S} 1$ in the SI).

\subsection{BACTRAPs}

Four monitoring wells differing in their hydrochemical characteristics were selected for the BACTRAP study to investigate the ETBE biodegradation under the following conditions: (Scenario 1) ETBE as main contaminant: (1a) unaltered redox conditions (PZ12) vs. (1b) scenario 1 subjected to biostimulation by oxygen injection (PZ17); (Scenario 2) ETBE plus PH: (2a) unaltered redox conditions (PZ8) vs. (2b) scenario 2 subjected to biostimulation by oxygen injection (PZ1) (Table 1).

Fatty acid profiles gained from all BACTRAPs were dominated by the saturated fatty acids

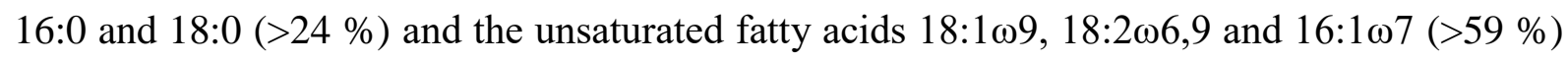
(Figure 2). The iso fatty acids i15:0 and i16:0 (<7\%) as well as the saturated fatty acids 14:0, 
15:0 and 20:0 $(<6 \%)$ were present at low abundance. The profiles showed that differences between the zones of ETBE as main contaminant and ETBE plus PH tend to be larger than between unaltered redox conditions and oxygen treatment (Figure 2).

In order to assess the biodegradation of ETBE, the ${ }^{13} \mathrm{C}$-incorporation from the ${ }^{13} \mathrm{C}$-labeled ETBE into total lipid fatty acids (TLFA) was determined. Due to low biomass on all BACTRAPs, carbon isotope signatures could be determined only for the most abundant fatty acids. In addition, fatty acid extraction from the pretreated Optiore L493 without any biomass revealed that the resin contained the fatty acid 18:1103 which could not be separated from the neighboring peak 18:1 19 by gas chromatography. Accordingly, carbon isotope signatures given for the 18:1 19 do not reflect the true isotope value of this peak but the bulk isotope

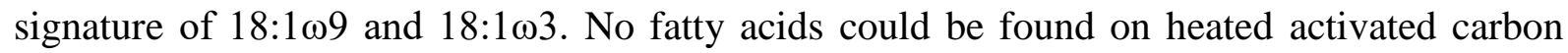
pellets serving as control.

Natural carbon isotope ratios of microbial fatty acids range from - $10 \%$ to $-36 \%$ o $[40,41]$. Fatty acids with a more positive carbon isotope signature are attributable to the assimilation of ETBEderived ${ }^{13} \mathrm{C}$-carbon. Significant ${ }^{13} \mathrm{C}$-enrichments were found on all BACTRAPs after 119 days of incubation. The extent of ${ }^{13} \mathrm{C}$-enrichment showed high variations in individual fatty acids and in dependence on the hydrochemical condition investigated (Table 2). BACTRAPs incubated in the zone with ETBE as main contaminant (PZ12 and PZ17) showed higher ${ }^{13} \mathrm{C}$ enrichments of individual fatty acids (up to $+1,144 \%$ ) under unaltered redox conditions (PZ12) compared to the well with oxygen injection (PZ17, up to $+102 \%$ ). The zone was characterized by the following pollutant mean concentrations before BACTRAP installation: ETBE: $265 \mu \mathrm{g}$ $\mathrm{L}^{-1}$, MTBE: $22 \mu \mathrm{g} \mathrm{L}^{-1}$, BTEX: $<1 \mu \mathrm{g} \mathrm{L}^{-1}$; TPH $<0.1 \mathrm{mg} \mathrm{L}^{-1}$ (Table 1). On the contrary, in the zone with higher concentrations of PH together with ETBE (mean PZ8 and PZ1 values before BACTRAP installation: ETBE: 2,600 $\mu \mathrm{g} \mathrm{L}^{-1}$, MTBE: $280 \mu \mathrm{g} \mathrm{L}^{-1}$, BTEX: $102 \mu \mathrm{g} \mathrm{L}^{-1}$; TPH: 9 $\mathrm{mg} \mathrm{L}^{-1}$ ), carbon isotope analysis of fatty acids revealed higher ${ }^{13} \mathrm{C}$-enrichments in the zone with oxygen treatment (up to $+9,228 \%$ in PZ1) than in the unaltered redox zone (up to $+906 \%$ in 
PZ8). However, on all BACTRAPs, 16:0 and 16:107 represented the fatty acids with the highest ${ }^{13} \mathrm{C}$-enrichments. Hydrochemical analysis revealed oxygen concentration up to $2.8 \mathrm{mg}$ $\mathrm{L}^{-1}$ in the wells subjected to oxygen injection. Additionally, methane was partially present (up to $380 \mu \mathrm{g} \mathrm{L}^{-1}$ ) as well as elevated concentration of iron (up to $6 \mathrm{mg} \mathrm{L}^{-1}$ ) and manganese (up to $1.2 \mathrm{mg} \mathrm{L}^{-1}$ ) (see Table 1 and Table S2 in the SI). In wells without oxygen injection, oxygen concentrations were, with one exception, below $0.8 \mathrm{mg} \mathrm{L}^{-1}$ and higher levels of methane (up to $940 \mu \mathrm{g} \mathrm{L}^{-1}$ ) as well as sulfide (up to $850 \mu \mathrm{g} \mathrm{L}^{-1}$ ) were detected.

\section{Discussion}

In this study, ETBE biodegradation was investigated in a contaminated aquifer by a combined application of CSIA and BACTRAPs loaded with ${ }^{13}$ C-labeled ETBE. CSIA showed no significant changes in the $\delta^{13} \mathrm{C}$-values of ETBE along the contaminant plume and only in the case of two groundwater wells slight enrichments in deuterium of up to $+14 \%$ indicating biodegradation of ETBE. Interestingly, no isotope shifts were observed in other wells with similar low ETBE concentrations. In a recent study, no changes in the carbon and hydrogen stable isotope signatures could be observed along an ETBE plume while the biodegradation of this groundwater pollutant could be proven by means of laboratory microcosms [5]. In microcosm experiments performed with the enrichment culture from that aquifer, low carbon and almost no hydrogen isotope fractionation were observed [5]. Taking into account the low carbon isotope enrichment factors $\varepsilon_{\mathrm{C}}$ of -0.4 to $-0.7 \%$ determined in that laboratory study and the average $\delta^{13} \mathrm{C}$-value of $-27.3 \%$ of that plume [5], a minimum of $94.7 \%$ degradation would be necessary to obtain a significant change in $\delta^{13} \mathrm{C}$-values of $+2 \%$ as suggested by the U.S. EPA [42]. Assuming that the enrichment culture comprised all ETBE degraders of the investigated field site [5], CSIA was probably not sensitive enough for detection of in situ biodegradation. So far, isotope fractionation of ETBE has been studied for six aerobic bacterial isolates exhibiting a high variability of carbon $\left(\varepsilon_{C}:-0.4\right.$ to $-1.7 \%$ ) and hydrogen enrichment 
factors ( $\varepsilon_{\mathrm{H}}$ : no fractionation to $-73 \%$ ) $[14,23,24]$. At the field site investigated in our study, elevated methane concentration and sulfide formation within the contaminant plume provided evidence on the prevalence of anoxic conditions at the time of CSIA monitoring. Stable isotope fractionation for the anaerobic biodegradation of ETBE has not been investigated so far due to the lack of anaerobic ETBE degrading cultures or isolates. The fact that low hydrogen isotope fractionation was observed in two groundwater wells while no fractionation was observed in other wells with similar ETBE concentration lead to the assumption that micro-environments might have developed which differ in their degradation capacities towards ETBE. It is also conceivable that different enzymatic mechanisms for the initial attack of ETBE occur causing differences in isotope fractionation [24].

When employing BACTRAPs amended with ${ }^{13} \mathrm{C}$-labeled ETBE in the framework of a field trial to enhance the biodegradation of petroleum compounds by oxygen injection, clear evidence of the biodegradation and assimilation of ETBE could be provided. Fatty acids extracted from all BACTRAPs were significantly enriched in ${ }^{13} \mathrm{C}$ with $\delta^{13} \mathrm{C}$-values of up to $+9,228 \%$ (corresponding to a ${ }^{13} \mathrm{C}$-fraction of $10.3 \%$ ), revealing that ETBE was degraded under all hydrochemical conditions investigated. Scenario 1 focused on the biodegradability of ETBE when it is the main contaminant. Hydrochemical analysis before BACTRAP installation in PZ12 and PZ17 revealed low oxygen concentrations (see SI, Table S2) which might still support efficient microaerophilic ETBE biodegradation as it was demonstrated in other laboratory studies with aerobic MTBE and ETBE degrading cultures [43]. When biostimulation was employed (scenario $1 \mathrm{~b}$ ), oxygen concentration increased to values up to $2.8 \mathrm{mg} \mathrm{L}^{-1}$ so that aerobic ETBE degradation can be expected. However, hydrochemical analysis provides indication on the redox processes but no substantiating evidence on the ongoing biodegradation process affecting a specific pollutant. Oxygen provided could also be utilized for oxidation of other organic compounds rather than ETBE or oxidation of reduced biodegradation products such as sulfide or methane [44]. Therefore, we can only speculate whether ETBE was degraded 
aerobically or anaerobically. From our results, it is also evident that ETBE was biodegraded in wells where PH, BTEX and MTBE were also present (Scenario 2) independently of the oxygen injection. Before BACTRAPs installation, both selected wells (PZ1 and PZ8) showed evidences for prevailing anoxic conditions (elevated methane and detectable sulfide concentrations) than scenario 1 (see Table 1 and Table S2 in the SI). However, during BACTRAP deployment, hypoxic conditions in PZ8 (oxygen up to $0.5 \mathrm{mg} \mathrm{L}^{-1}$ ) and oxygen concentrations in PZ1 up to $2 \mathrm{mg} \mathrm{L}^{-1}$ together with the presence of sulfide and methane lead to the assumption of aerobic and anaerobic ETBE biodegradation in close vicinity. Whether the biodegradation of ETBE was slowed down in the presence of BTEX as observed in a laboratory study with Rhodococcus wratislaviensis IFP 2017 or it was stimulated by the presence of petroleum hydrocarbons due to a co-metabolic degradation [11] cannot be clarified by our results. The BACTRAP approach cannot distinguish between the incorporation of ${ }^{13} \mathrm{C}$-labeled ETBE as primary carbon substrate or a cometabolic process where ${ }^{13} \mathrm{C}$-labeled ETBE is degraded to another metabolite which further is utilized as carbon source. For certain, an inhibition of the ETBE degradation did not occur in the presence of MTBE and BTEX under tested in situ conditions as reported in the referred study [11].

The high variability in ${ }^{13} \mathrm{C}$-enrichment of fatty acids might be explained by the different biodegradation rates of ETBE but also assimilation of unlabeled ETBE and other carbon sources present in the aquifer. Generally, highest ${ }^{13} \mathrm{C}$-enrichments were found on all BACTRAPs in the fatty acids $16: 0$ and $16: 1 \omega 7$. The latter is a biomarker of gram-negative bacteria [45-47], suggesting the relevance of those species for the ETBE biodegradation at the field site. Examples of so far described ETBE gram-negative aerobic degraders are Comamonas testosteroni E1 which was isolated from ETBE-gasoline-polluted soil [48] and Aquincola tertiaricarbonis L108 [10]. Both of them are able to grow on ETBE as the sole source of carbon. Under anoxic conditions, although not specifically for ETBE, MTBE anaerobic degraders 
belonging to the gram-negative genus Sphingopyxis have been recently identified by DNA-SIP in methanogenic microcosms from wastewater treatment plant samples [49].

Comparison of CSIA and the BACTRAP approach revealed differences with respect to the sensitivity of biodegradation detection. While CSIA provided low indication on the biodegradation of ETBE, conclusive evidence has been received by the BACTRAPs. Taking the most positive carbon and hydrogen isotope signature of ETBE determined for the high contaminated groundwater wells $\left(\delta^{13} \mathrm{C}:-25.4 \%, \delta^{2} \mathrm{H}:-126 \%\right)$ and the enrichment factors from literature ( $\varepsilon_{\mathrm{C}}:-0.4$ to $-1.7 \%$, $\varepsilon_{\mathrm{H}}$ : no fractionation to $-73 \%$ ), minimal biodegradation between 70 and $99 \%$ for carbon isotope analysis and 27 and $90 \%$ for hydrogen isotope analysis would have been required for its detection by CSIA (see SI, Table S3). A much more sensitive detection of ETBE biodegradation is possible with the BACTRAP approach. Based on the analytical precision of $\pm 0.5 \%$ obtained for carbon isotope analysis by GC-IRMS, changes of only $1 \%$ can be detected which reflect changes in the relative ${ }^{13} \mathrm{C}$ fraction of about $0.001 \%$.

\section{Conclusion}

Our results demonstrated that ETBE can be degraded in situ both when ETBE is the main contaminant and when ETBE is accompanied by other petroleum compounds such as BTEX and MTBE. Based on the hydrochemical analysis, aerobic and anaerobic degradation of ETBE could be expected at the field site. According to the present knowledge and results obtained, CSIA would require a high degree of ETBE biodegradation to be detectable but generally has the potential to quantify the in situ biodegradation of organic pollutants [22]. The BACTRAPs allows a sensitive detection of the in situ biodegradation of ETBE but a quantitative evaluation is challenging. Future work may focus on isolation, identification and physiological characterization of the key microorganisms, especially those capable of the anaerobic ETBE degradation, in order to understand the microbial fate of ETBE in the environment and to take advantage of such natural processes for the cleanup of contaminated field sites. 


\section{Acknowledgements}

The development of the BACTRAP system for ETBE was financially supported within a German ZIM-project funded by the Federal Ministry of Economics and Technology (BMWi) (project number: KF2081007RH9). Mònica Rosell was supported by a Beatriu de Pinós postdoctoral grant (2008 BP-A 00054) from the Autonomous Government of Catalonia (Agència de Gestió d'Ajuts Universitaris i de Recerca, AGAUR). We further thank Matthias Gehre and Ursula Günther for their technical support in isotope analysis as well as Isabel Mori, Jacinto Villanueva Redondo and Stefan Recht for providing geological and hydraulic field site information.

\section{References}

[1] CONCAWE, Gasoline ether oxygenate occurence in europe, and a review of their fate and transport characteristics in the environment, Brussels, 2012. https://www.concawe.eu/Content/Default.asp

[2] EU, Directive 2003/30/EC on the promotion of the use of biofuels or other renewable fuels for transport, Official Journal of the European Union, European Parliament and the Concil 2003. http://ec.europa.eu/energy/renewables/biofuels/biofuels_en.htm

[3] EU, Directive 2009/28/EC on the promotion of the use of energy from renewable sources, Official Journal of the European Union, European Parliament and the Concil 2009. http://ec.europa.eu/energy/renewables/biofuels/biofuels_en.htm

[4] A. van Wezel, L. Puijker, C. Vink, A. Versteegh, P. de Voogt, Odour and flavour thresholds of gasoline additives (MTBE, ETBE and TAME) and their occurrence in dutch drinking water collection areas, Chemosphere, 76 (2009) 672-676.

[5] F. Fayolle-Guichard, J. Durand, M. Cheucle, M. Rosell, R.J. Michelland, J.P. Tracol, F. Le Roux, G. Grundman, O. Atteia, H.H. Richnow, A. Dumestre, Y. Benoit, Study of an aquifer 
contaminated by ethyl tert-butyl ether (ETBE): Site characterization and on-site bioremediation, J. Hazard. Mater., 201 (2012) 236-243.

[6] T. Shih, Y. Rong, T. Harmon, M. Suffet, Evaluation of the impact of fuel hydrocarbons and oxygenates on groundwater resources, Environ. Sci. Technol., 38 (2004) 42-48.

[7] I. Declercq, V. Cappuyns, Y. Duclos, Monitored natural attenuation (MNA) of contaminated soils: State of the art in Europe-a critical evaluation, Sci. Total Environ., 426 (2012) 393-405. [8] P. Bombach, H.H. Richnow, M. Kästner, A. Fischer, Current approaches for the assessment of in situ biodegradation, Appl Microbiol Biotechnol, 86 (2010) 839-852.

[9] F. Fayolle, G. Hernandez, F. Le Roux, J.P. Vandecasteele, Isolation of two aerobic bacterial strains that degrade efficiently ethyl t-butyl ether (ETBE), Biotechnol. Lett., 20 (1998) 283286.

[10] U. Lechner, D. Brodkorb, R. Geyer, G. Hause, C. Hartig, G. Auling, F. Fayolle-Guichard, P. Piveteau, R.H. Müller, T. Rohwerder, Aquincola tertiaricarbonis gen. Nov., sp nov., a tertiary butyl moiety-degrading bacterium, Int. J. Syst. Evol. Microbiol., 57 (2007) 1295-1303. [11] M. Auffret, D. Labbe, G. Thouand, C.W. Greer, F. Fayolle-Guichard, Degradation of a mixture of hydrocarbons, gasoline, and diesel oil additives by Rhodococcus aetherivorans and Rhodococcus wratislaviensis, Appl. Environ. Microbiol., 75 (2009) 7774-7782.

[12] Y. Digabel, S. Demanèche, Y. Benoit, T. Vogel, F. Fayolle-Guichard, Ethyl tert-butyl ether (ETBE) biodegradation by a syntrophic association of Rhodococcus sp. IFP 2042 and Bradyrhizobium sp. Ifp 2049 isolated from a polluted aquifer, Appl. Microbiol. Biotechnol., (2013) 1-9.

[13] R.J. Steffan, K. McClay, S. Vainberg, C.W. Condee, D.L. Zhang, Biodegradation of the gasoline oxygenates methyl tert-butyl ether, ethyl tert-butyl ether, and tert-amyl methyl ether by propane-oxidizing bacteria, Appl. Environ. Microbiol., 63 (1997) 4216-4222.

[14] J.R. McKelvie, M.R. Hyman, M. Elsner, C. Smith, D.M. Aslett, G. Lacrampe-Couloume, B. Sherwood Lollar, Isotopic fractionation of methyl tert-butyl ether suggests different initial 
reaction mechanisms during aerobic biodegradation, Environ. Sci. Technol., 43 (2009) 27932799.

[15] C.K. Yeh, J.T. Novak, Anaerobic biodegradation of gasoline oxygenates in soils, Water Environ. Res., 66 (1994) 744-752.

[16] J.M. Suflita, M.R. Mormile, Anaerobic biodegradation of known and potential gasoline oxygenates in the terrestrial subsurface, Environ. Sci. Technol., 27 (1993) 976-978.

[17] P. Somsamak, R.M. Cowan, M.M. Häggblom, Anaerobic biotransformation of fuel oxygenates under sulfate-reducing conditions, FEMS Microbiol. Ecol., 37 (2001) 259-264.

[18] M.M. Häggblom, L.K.G. Youngster, P. Somsamak, H.H. Richnow, Anaerobic biodegradation of methyl tert-butyl ether (MTBE) and related fuel oxygenates, A.I. Laskin, S. Sariaslani, G.M. Gadd (Eds.) Adv. Appl. Microbiol., vol 62, 2007, pp. 1-20.

[19] C. Malandain, F. Fayolle-Guichard, T.M. Vogel, Cytochromes P450-mediated degradation of fuel oxygenates by environmental isolates, FEMS Microbiol. Ecol., 72 (2010) 289-296.

[20] R.U. Meckenstock, B. Morasch, C. Griebler, H.H. Richnow, Stable isotope fractionation analysis as a tool to monitor biodegradation in contaminated aquifers, J. Contam. Hydrol., 75 (2004) 215-255.

[21] C.M. Aelion, R. Aravena, D. Hunkeler, P. Höhener, Environmental isotopes in biodegradation and bioremediation, CRC Press, Boca Raton, 2010.

[22] M. Thullner, F. Centler, H.H. Richnow, A. Fischer, Quantification of organic pollutant degradation in contaminated aquifers using compound specific stable isotope analysis - review of recent developments, Org. Geochem., 42 (2012) 1440-1460.

[23] M. Rosell, D. Barcelo, T. Rohwerder, U. Breuer, M. Gehre, H.H. Richnow, Variations in $13 \mathrm{C} / 12 \mathrm{C}$ and $\mathrm{D} / \mathrm{H}$ enrichment factors of aerobic bacterial fuel oxygenate degradation, Environ. Sci. Technol., 41 (2007) 2036-2043. 
[24] M. Rosell, R. Gonzalez-Olmos, T. Rohwerder, K. Rusevova, A. Georgi, F.D. Kopinke, H.H. Richnow, Critical evaluation of the 2D-CSIA scheme for distinguishing fuel oxygenate degradation reaction mechanisms, Environ. Sci. Technol., 46 (2012) 4757-4766.

[25] J. Busch-Harris, K. Sublette, K.P. Roberts, C. Landrum, A.D. Peacock, G. Davis, D. Ogles, W.E. Holmes, D. Harris, C. Ota, X.M. Yang, A. Kolhatkar, Bio-traps coupled with molecular biological methods and stable isotope probing demonstrate the in situ biodegradation potential of MTBE and TBA in gasoline-contaminated aquifers, Ground Water Monit. Remediat., 28 (2008) 47-62.

[26] R. Geyer, A.D. Peacock, A. Miltner, H.H. Richnow, D.C. White, K.L. Sublette, M. Kästner, In situ assessment of biodegradation potential using biotraps amended with 13Clabeled benzene or toluene, Environ. Sci. Technol., 39 (2005) 4983-4989.

[27] M. Kästner, A. Fischer, I. Nijenhuis, R. Geyer, N. Stelzer, P. Bombach, C.C. Tebbe, H.H. Richnow, Assessment of microbial in situ activity in contaminated aquifers, Eng. Life Sci., 6 (2006) 234-251.

[28] N. Stelzer, C. Büning, F. Pfeifer, A.B. Dohrmann, C.C. Tebbe, I. Nijenhuis, M. Kästner, H.H. Richnow, In situ microcosms to evaluate natural attenuation potentials in contaminated aquifers, Org. Geochem., 37 (2006) 1394-1410.

[29] I. Nijenhuis, N. Stelzer, M. Kästner, H.H. Richnow, Sensitive detection of anaerobic monochlorobenzene degradation using stable isotope tracers, Environ. Sci. Technol., 41 (2007) $3836-3842$.

[30] N. Stelzer, G. Imfeld, M. Thullner, J. Lehmann, A. Poser, H.H. Richnow, I. Nijenhuis, Integrative approach to delineate natural attenuation of chlorinated benzenes in anoxic aquifers, Environ. Pollut., 157 (2009) 1800-1806.

[31] F.A. Herbst, A. Bahr, M. Duarte, D. Pieper, H.H. Richnow, M. von Bergen, J. Seifert, P. Bombach, Elucidation of in situ polycyclic aromatic hydrocarbon degradation by functional metaproteomics (protein-SIP), J. Proteomics, 13 (2013) 2910-2920. 
[32] T.B. Coplen, Guidelines and recommended terms for expression of stable-isotope-ratio and gas-ratio measurement results, Rapid Commun. Mass Spectrom., 25 (2011) 2538-2560.

[33] R. Gonfiantini, W. Stichler, K. Rozanski, Standards and intercomparison materials for stable isotopes of light elements, Vienna, 1995, pp. 13-29.

[34] P. Bombach, A. Chatzinotas, T.R. Neu, M. Kästner, T. Lueders, C. Vogt, Enrichment and characterization of a sulfate-reducing toluene-degrading microbial consortium by combining in situ microcosms and stable isotope probing techniques, FEMS Microbiol. Ecol., 71 (2010) 237246.

[35] E.P. Bi, S.B. Haderlein, T.C. Schmidt, Sorption of methyl tert-butyl ether (MTBE) and tert-butyl alcohol (TBA) to synthetic resins, Water Res., 39 (2005) 4164-4176.

[36] B. Morasch, E. Annweiler, R.J. Warthmann, R.U. Meckenstock, The use of a solid adsorber resin for enrichment of bacteria with toxic substrates and to identify metabolites: Degradation of naphthalene, $o-$, and $m$-xylene by sulfate-reducing bacteria, J. Microbiol. Methods, 44 (2001) 183-191.

[37] J.B. Guckert, C.P. Antworth, P.D. Nichols, D.C. White, Phospholipid, ester-linked fatty acid profiles as reproducible assays for changes in prokaryotic community structure of estuarine sediments, FEMS Microbiol. Ecol., 31 (1985) 147-158.

[38] F. Bastida, S. Jechalke, P. Bombach, A.G. Franchini, J. Seifert, M. von Bergen, C. Vogt, H.H. Richnow, Assimilation of benzene carbon through multiple trophic levels traced by different stable isotope probing methodologies, FEMS Microbiol. Ecol., 77 (2011) 357-369.

[39] C. Ratledge, S.G. Wilkinson, Microbial lipids, Academic Press, San Diego, 1989.

[40] W.-R. Abraham, C. Hesse, O. Pelz, Ratios of carbon isotopes in microbial lipids as an indicator of substrate usage, Appl. Environ. Microbiol., 64 (1998) 4202-4209.

[41] S.A. Pombo, O. Pelz, M.H. Schroth, J. Zeyer, Field-scale 13C-labeling of phospholipid fatty acids (PLFA) and dissolved inorganic carbon: Tracing acetate assimilation and 
mineralization in a petroleum hydrocarbon-contaminated aquifer, FEMS Microbiol. Ecol., 41 (2002) 259-267.

[42] U.S.-EPA, A guide for assessing biodegradation and source identification of organic ground water contaminants using compound specific isotope analysis (CSIA), Office of Research and Development, Ada, 2008. http://cfpub.epa.gov/si/si_public_record_Report.cfm?dirEntryId=202171\&CFID=174436588 $\&$ CFTOKEN=94780555 $\&$ jsessionid $=8630 \mathrm{c} 653 \mathrm{cbc} 48 \mathrm{ca} 1762 \mathrm{e} 427 \mathrm{c} 104044683143$

[43] M. Rosell, S. Finsterbusch, S. Jechalke, T. Hübschmann, C. Vogt, H.H. Richnow, Evaluation of the effects of low oxygen concentration on stable isotope fractionation during aerobic MTBE biodegradation, Environ. Sci. Technol., 44 (2010) 309-315.

[44] S. Feisthauer, M. Seidel, P. Bombach, S. Traube, K. Knöller, M. Wange, S. Fachmann, H.H. Richnow, Characterization of the relationship between microbial degradation processes at a hydrocarbon contaminated site using isotopic methods, J. Contam. Hydrol., 133 (2012) 17 29.

[45] C.T. Green, K.M. Scow, Analysis of phospholipid fatty acids (PLFA) to characterize microbial communities in aquifers, Hydrol. J., 8 (2000) 126-141.

[46] S.E. Leckie, Methods of microbial community profiling and their application to forest soils, For. Ecol. Manage., 220 (2005) 88-106.

[47] A. Kaur, A. Chaudhary, A. Kaur, R. Choudhary, R. Kaushik, Phospholipid fatty acid - a bioindicator of environment and assessment in soil ecosystem, Curr. Sci., 89 (2005) 1103-1112. [48] M. Kharoune, L. Kharoune, J.M. Lebeault, A. Pauss, Isolation and characterization of two aerobic bacterial strains that completely degrade ethyl tert-butyl ether (ETBE), Appl. Microbiol. Biotechnol., 55 (2001) 348-353.

[49] W.M. Sun, X.X. Sun, A.M. Cupples, Anaerobic methyl tert-butyl ether-degrading microorganisms identified in wastewater treatment plant samples by stable isotope probing, Appl. Environ. Microbiol., 78 (2012) 2973-2980. 


\section{Figures}

\section{$\underline{\text { Figure } 1}$}

Distribution of ETBE concentrations and carbon as well as hydrogen isotope signatures of ETBE of selected groundwater wells in December 2011. For the nine groundwater wells investigated, ETBE concentration (in $\mu \mathrm{g} \mathrm{L}^{-1}$ ) and carbon as well hydrogen isotope signatures (in \%) are given. Isotope signatures are reported as means of replicate measurements \pm analytical standard deviation. Ten month later, BACTRAPs were deployed in the monitoring wells PZ1, PZ8, PZ12 and PZ17 to investigate the ETBE biodegradation under the following conditions: (Scenario 1) ETBE as main contaminant: (1a) unaltered redox conditions (PZ12) vs. (1b) scenario 1 subjected to biostimulation by oxygen injection (PZ17); (Scenario 2) ETBE plus PH: (2a) unaltered redox conditions (PZ8) vs. (2b) scenario 2 subjected to biostimulation by oxygen injection (PZ1).

\section{Figure 2}

Relative abundance of total lipid fatty acids (given as FAMEs) derived from BACTRAPs after 119 days of incubation in groundwater wells with (i) ETBE as main contaminant (ETBE), (ii) ETBE as main contaminant subjected to oxygen injection (ETBE+O2), (iii) ETBE plus other petroleum hydrocarbons (ETBE+PH) and (iv) ETBE plus other petroleum hydrocarbons subjected to oxygen injection $(\mathrm{ETBE}+\mathrm{PH}+\mathrm{O} 2)$.

\section{Tables}

\section{Table 1}

Temperature and $\mathrm{pH}$ as well as concentration of main organic compounds, electron acceptors and reduced products determined in groundwater wells before (September 2011) and after BACTRAP deployment (January 2012). PZ12: ETBE, PZ17: ETBE+O 2 ; PZ8: ETBE+PH, $\mathrm{PZ1}: \mathrm{ETBE}+\mathrm{PH}+\mathrm{O}_{2}$. na $=$ not analyzed due to breaking of the glass bottle 


\section{$\underline{\text { Table } 2}$}

Carbon isotope signatures of total lipid fatty acids (in \%o) derived from BACTRAPs after 119 days of incubation in four different groundwater wells. BACTRAPs were incubated in groundwater wells with (i) ETBE as main contaminant (ETBE), (ii) ETBE as main contaminant subjected to oxygen injection $\left(\mathrm{ETBE}+\mathrm{O}_{2}\right)$, (iii) ETBE plus other petroleum hydrocarbons (ETBE+PH) and (iv) ETBE plus other petroleum hydrocarbons subjected to oxygen injection $\left(\mathrm{ETBE}+\mathrm{PH}+\mathrm{O}_{2}\right)$. Values are reported as means of triplicate measurements. ${ }^{1}$ Bulk carbon

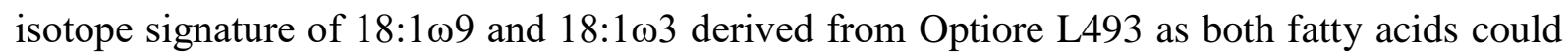
not be separated by gas chromatography. nd: not detectable due to low abundance or unsufficient separation of fatty acids from other organic compounds. 